\title{
Genistein-induced differentiation of breast cancer stem/progenitor cells through a paracrine mechanism
}

\author{
YANCHEN LIU ${ }^{1 *}$, TIANBIAO ZOU ${ }^{2 *}$, SHUHUAI WANG $^{3}$, HONG CHEN $^{3}$, DONGJU SU $^{4}$, \\ XIAONA FU ${ }^{3}$, QINGYUAN ZHANG ${ }^{3}$ and XINMEI KANG ${ }^{3}$ \\ ${ }^{1}$ The First Affiliated Hospital of Harbin Medical University; ${ }^{2}$ The Fifth Hospital of Harbin City; \\ ${ }^{3}$ The Third Affiliated Hospital of Harbin Medical University; ${ }^{4}$ The Second Affiliated Hospital \\ of Harbin Medical University, Harbin, Heilongjiang, P.R. China
}

Received October 14, 2015; Accepted November 18, 2015

DOI: $10.3892 /$ ijo.2016.3351

\begin{abstract}
It is believed that breast cancer stem cells (BCSCs), like normal stem cell counterparts, have the capacity of selfrenewal and differentiation. Simultaneously, estrogen receptor (ER)-negative (-) BCSCs are affected by surrounding differentiated ER-positive (+) tumor cells by virtue of paracrine signaling within the tumor microenvironment. Genistein (GEN), as a sort of phytoestrogen, can act on $\mathrm{ER}^{+}$breast cancer cells but the role of GEN in the differentiation of neighboring ER BCSCs has not been defined. Transwell co-culture system was utilized so as to elaborate the interaction between welldifferentiated $\mathrm{ER}^{+}$breast cancer cells (MCF-7) and ER- breast cancer stem/progenitor cells (mammospheres derived from MDA-MB-231 cells). GEN-induced differentiation of BCSCs was analyzed by mammospheres formation assay, flow cytometry and RT-PCR after a 3 day solo-culture or co-culture. We find that GEN sized $2 \mu \mathrm{M}$, and $40 \mathrm{nM}$, effectively promotes morphological alteration of mammospheres, reduces the ratio of subset of $\mathrm{CD}^{2} 4^{+} / \mathrm{CD} 24^{-} / \mathrm{ESA}^{+}$cells and upregulates the expression of differentiated cell markers of mammospheres in co-culture system, but not in solo-culture condition. Besides, we demonstrate that the differentiation-inducing effect of GEN on mammospheres is associated with PI3K/ Akt and MEK/ERK signaling pathways which are activated by amphiregulin released from $\mathrm{ER}^{+}$cancer cells. These results indicate that GEN was able to induce the differentiation of breast cancer stem/progenitor cells through interaction with $\mathrm{ER}^{+}$cancer cells by a paracrine mechanism.
\end{abstract}

Correspondence to: Dr Xinmei Kang, The Third Affiliated Hospital of Harbin Medical University, Haping Road 150 of Nangang District, Harbin, Heilongjiang, P.R. China

E-mail: kxm19791107@163.com

${ }^{*}$ Contributed equally

Key words: genistein, differentiation, stem cells, paracrine

\section{Introduction}

It was recently proposed that cancer stem cells (CSCs) play vital roles in tumor initiation, relapse, metastasis and resistance to conventional treatment $(1,2)$. CSCs are a small population of tumor cells with the capacity of self-renewal and differentiation, in other words they behave like normal stem cells which are pluripotent to give rise to heterogeneous tumor phenotypes under different circumstances (3). When chemotherapy kills the bulk of tumors but fails to kill CSCs, the surviving CSCs are able to generate new tumors after a period (4). Likewise, endocrine-therapy-resistant estrogen receptor (ER)-positive (+) breast cancers could enrich ER-negative (-) CSC population (5). Taking these viewpoints into consideration, drugs that can kill CSCs effectively are helpful to confront tumor cells when the treatment becomes invalid. Besides, another strategy is to induce CSCs to differentiate into matured tumor cells which are more susceptible and effective for treatment (6). In either case, targeting CSCs or inducing differentiation of CSCs could have profound influence on cancer therapy and be beneficial to cancer eradication.

The existence of CSCs was verified in acute myelogenous leukemia for the first time, more recently, in solid tumors, such as breast, prostate, brain and colon cancers (7-9), each of which has the expression of characteristic cell surface marker. For example, $\mathrm{CD}_{4} 4^{+} / \mathrm{CD} 24 / \mathrm{ESA}^{+}$phenotype breast cancer cells that are able to give rise to tumors in the mammary fat pad of NOD/SCID mice have CSC properties (7). Furthermore, $\mathrm{CD} 44^{+} / \mathrm{CD} 24 \% \mathrm{ESA}^{+}$cells isolated from breast cancer cells display the stem cell-like ability of self-renewal and resistance to chemotherapy $(4,5)$. Clinical evidence has shown that breast cancer patients with the phenotype of $\mathrm{CD} 44^{+} / \mathrm{CD} 24^{-} / \mathrm{ESA}^{+}$ have shorter disease-free interval and overall survival (10). Breast cancer cells, when cultured in serum-free medium growing as spherical clusters, are called mammosphere cells which are undifferentiated but able to adhere into plates and differentiate into epithelial-like cells under differentiated conditions (11). Hence, a subpopulation of cells displaying a specific $\mathrm{CD}_{4} 4^{+} / \mathrm{CD}^{2} 4^{-} / \mathrm{ESA}^{+}$in mammospheres is considered as breast cancer stem/progenitor cells in our experiment.

In normal mammary gland development, the role of ER is essential for proliferation of terminal end buds (TEBs) that 
cause the ducal elongation (12). Previous studies have exhibited normal stem cell and breast cancer stem cell (BCSC) pools both lack ER expression (13). In early stage, ER- stem cell population give rises to ER ${ }^{-}$progenitor cells (myoepithelial cells, ductal epithelial cells) and $\mathrm{ER}^{+}$progenitor cells asymmetrically, which secrete some paracrine factors in response to estrogen to stimulate the proliferation and differentiation of ER- cells in turn (14). Consequently, the stem cell microenvironment comprises stem cell compartment (ER-) and more differentiated cells $\left(\mathrm{ER}^{-}, \mathrm{ER}^{+}\right)$that maintain their stemness $(15,16)$. Similarly, the analogous developmental hierarchy containing CSCs and more differentiated cells is supported in epithelial and other solid tumors. The studies come up with a question: will the well-differentiated $\mathrm{ER}^{+}$breast cancer cells have paracrine effect on ER- BCSCs when exposed to exogenous stimulation?

It is now believed that in the early development, breast cancer can be influenced by nutrition (17). Compared with women in western countries, the incidence of breast cancer is suggested to be lower in Asian women, which has a certain relationship with dietary intake of soy isoflavone genistein (GEN) (18). It is generally considered that during childhood and adolescence, high intake of soy foods could promote differentiation of mammary gland $(19,20)$ to prevent the development of breast cancer. However, it remains disputable whether it is effective in adult breast cancer patients. Given that GEN as a sort of phytoestrogen binds to ER when the local estrogen concentration is low (21), we raise an envisage possibility that GEN acts on $\mathrm{ER}^{+}$breast cancer cells secreting certain factor to promote the differentiation of neighboring $\mathrm{ER}^{-}$breast cancer stem/progenitor cells in the process.

Based on the studies reviewed above, we used Transwell inserts to conduct a co-culture model to simulate the heterogeneity of breast tumors wherein $\mathrm{ER}^{+}$cells (MCF-7) and $\mathrm{ER}^{-}$stem cells (mammasphere cells derived from MDA-MB231) were separated to analyze paracrine effect of GEN on BCSCs. We also investigated the direct impact of GEN on the proliferation and differentiation of breast cancer stem/ progenitor cells in vitro. We found that GEN-induced differentiation of breast cancer stem-like/progenitor cells was proved in co-culture system but not in solo-culture condition. We also provided proof suggesting a possible mechanism of how the differentiation-inducing activity occured.

\section{Materials and methods}

Cell lines and reagents. The human breast cancer cell lines MCF-7 and MDA-MB-231 were obtained from Shanghai Institutes for Biological Sciences. Both cells were cultured in phenol-red-free DMEM (Hyclone) supplemented with 10\% charcoal-dextran stripped FBS (Biological industries) and $1 \%$ antibiotic-antimycotic solution (Invitrogen) in a humidified incubator at $37^{\circ} \mathrm{C}$ with $5 \% \mathrm{CO}_{2}$. GEN, 17- $\beta$ estradiol and dimethyl sulfoxide (DMSO) were purchased from SigmaAldrich.

Mammosphere culture and mammosphere formation assay. For mammosphere culture, MDA-MB-231 cells were suspended at 10,000 cells $/ \mathrm{ml}$, seeded into 6-well ultra-low attachment plates (Greiner) in serum free DMEM/F12 (1:1)
(Hyclone) containing $20 \mathrm{ng} / \mathrm{ml}$ epidermal growth factor (EGF, Peprotech), $10 \mathrm{ng} / \mathrm{ml}$ basic fibroblast growth factor (bFGF, Peprotech), 2\% B27 (Invitrogen), and $0.4 \%$ bovine serum albumin (Sigma-Aldrich). On day 6 or 7 , the first passage mammospheres (P1) were collected, dissociated into singlecell suspension mechanically, and replated in solo-culture or co-culture condition with treatment of GEN or DMSO. After a 3 day solo-culture or co-culture, the second passage of mammosphere cells (P2) were obtained and manually counted by inverted phase-contrast Zeiss Axiovert 25 microscope.

Co-culture condition. Six-well Transwell inserts (CorningCostar) that had a polycarbonate membrane with a pore size of $0.4 \mu \mathrm{m}$ were used to conduct a co-culture model. The membrane allowed exchange of components of medium such as proteins and small molecules while prevented cell migration between the two chambers. MCF-7 cells were seeded in the Transwell inserts at the density of $5 \times 10^{4}$ cells/well. Suspension of mammospheres cells (P1) was added in the bottom chamber at the same density. The bottom chamber used in the experiments is 6-well ultra-low attachment plate for cell suspension culture. A diluted concentration of GEN $(2 \mu \mathrm{M}$, and $40 \mathrm{nM})$ or DMSO was added in the medium of MCF-7 cells and mammosphere cells (P2) in the bottom chamber were collected during 3 days of co-culture for following experiments (Fig. 1).

Isolation of RNA and quantitative RT-PCR. The mammosphere cells (P2) in co-culture and solo-culture condition were harvested and total RNA was prepared using TRIzol (Invitrogen) following the manufacturer's protocols. Then RNA samples were converted into cDNA by PrimeScript ${ }^{\mathrm{TM}}$ RT Reagent kit (Takara). Synthesized cDNA was subjected to quantitative RT-PCR using a SYBR Green Master Mix kit (Invitrogen) according to the manufacturer's protocols. Fold changes of relative gene expression were calculated by $2^{-\Delta \Delta \mathrm{Ct}}$ and the expression of $\beta$-actin was used as internal control. The primers for differentiation and stem state genes are presented in Table I.

Flow cytometric analysis. The mammosphere cells (P2) harvested were disaggregated gently, suspended as singlecells and stained with anti-CD44-APC, anti-CD24-FITC, anti-EpCAM-PE (Ebioscience), or their corresponding isotypematched controls (Ebioscience) according to manufacturer's protocol. After washing steps, the cells were analysed by flow cytometry (BD FACS Aria).

Protein extraction and western blot analysis. The mammosphere cell (P2) lysates were prepared and loaded onto SDS-electrophoresis gel and transferred to nitrocellulose membranes. Membranes were incubated with primary antibodies against phospho- $\beta$-catenin, $\beta$-catenin, phosphoAkt (308), phospho-Akt (473), Akt (pan), phospho-ERK1/2, ERK1/2, Gsk3 $\beta$, phospho-Smad2/3, Smad2/3, TGF- $\beta$ (Cell Signaling Technology) or $\beta$-actin (Abcam), overnight at $4^{\circ} \mathrm{C}$. After washing steps with Tris-buffered saline with Tween-20 (TBST), the membranes were incubated with Alexa Fluor 800-labeled goat anti-rabbit IgG (KPL) for $1 \mathrm{~h}$ at room temperature. Specific proteins were detected and quantified using the Odyssey system (Li-Cor). 


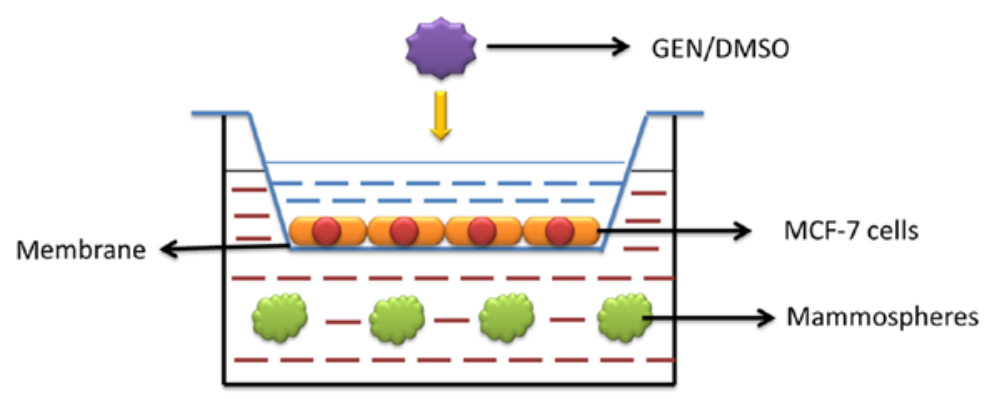

Figure 1. Tranwell inserts were utilized to establish co-culture condition between ER ${ }^{+}$and ER cells. The construction of Transwell co-culture condition contributes to exploring the interaction between well-differentiated $\mathrm{ER}^{+}$cells and ER stem cells. The ER- breast cancer stem/progenitor cells were plated in the lower chamber of co-cultured condition, while ER ${ }^{+}$MCF-7 cells were seeded in the Transwell inserts (upper chamber). The size of membrane separated the two chambers was only $0.4 \mu \mathrm{m}$ allowing the passage of small molecules but not two sorts of cells. GEN ( $2 \mu \mathrm{M}$, and $40 \mathrm{nM})$ or DMSO was added in the medium of upper chamber. Since GEN as small molecule could freely go through the membrane, the direct effect of GEN on ER' breast cancer stem/progenitor cells was also assessed in our study.

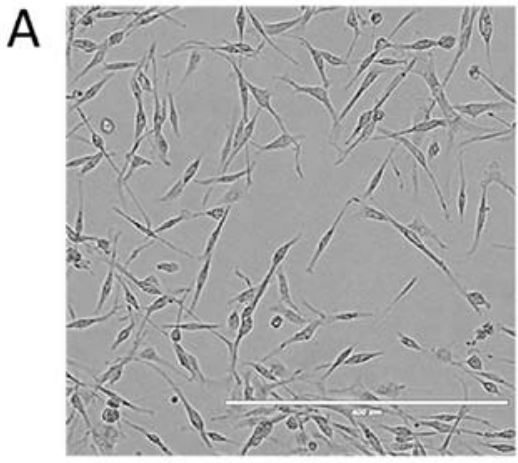

MDA-MB-231 cells

B

Co-cultured mammosphere cells(P2)
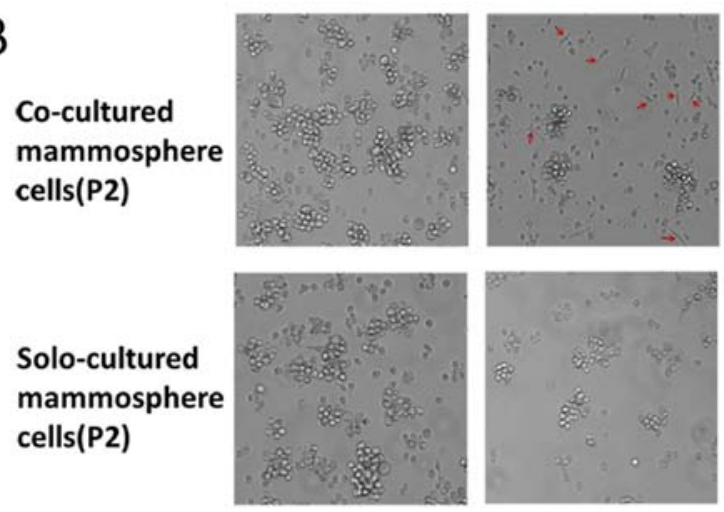

DMSO
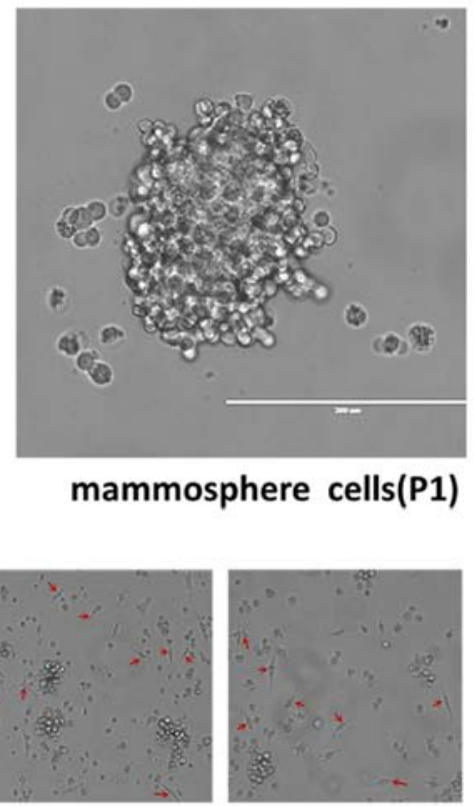

mammosphere cells(P1)

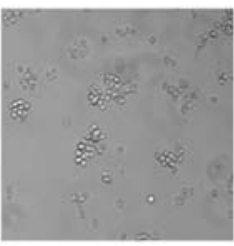

40 nmGEN

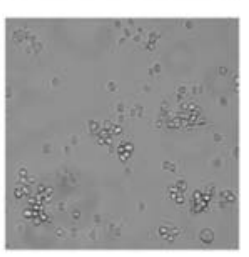

$2 \mu \mathrm{mGEN}$

C

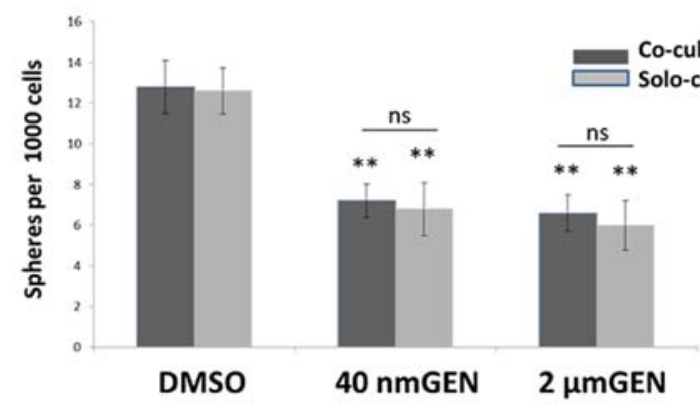

Figure 2. GEN (2 $\mu \mathrm{M}, 40 \mathrm{nM})$ significantly inhibited mammosphere formation both in co-culture and solo-culture condition. (A) Breast cancer line MDA-MB-231 cells presenting with long spindle-shaped adherent growth were seeded in ultra-low attachment 6-well plates with serum free medium for 6 or 7 days and formed mammospheres (P1). (B) During 3 days of co-culture or solo-culture, the photos of mammosphere (P2) morphology were shown and the changes of morphology in co-culture system were marked with a red arrow. Images were taken under a light microscope at a magnification of $x 100$ and representative of three randomly selected fields. (C) The mammospheres were counted in each group (data were mean \pm SD; $n=4,{ }^{* *} \mathrm{P}<0.01 ; \mathrm{ns}$, not significant, relative to the values in the respective controls). 
A

DMSO

GEN40 $\mathrm{nm}$

GEN2 $\mu \mathrm{m}$
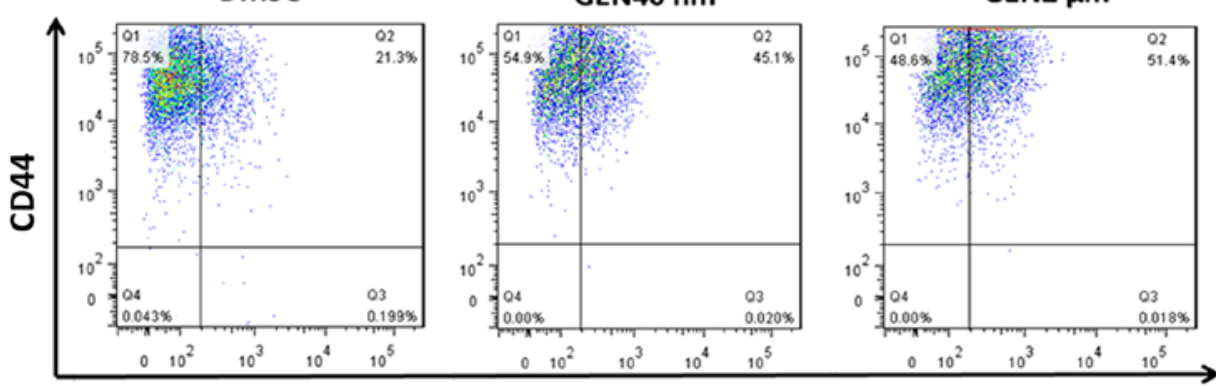

CD24

B

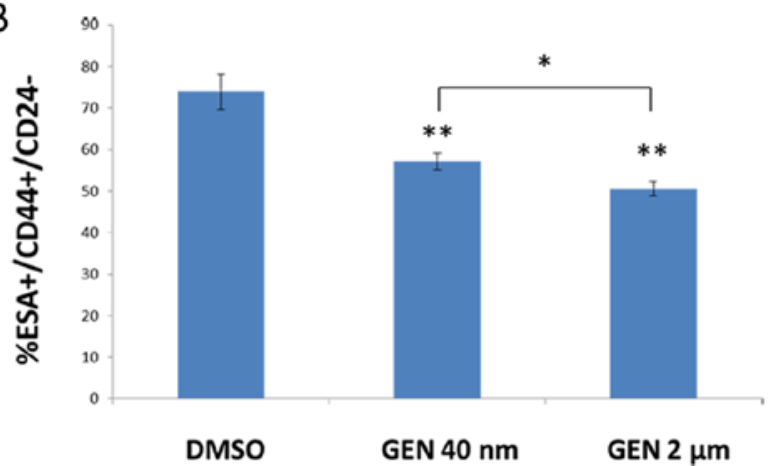

Figure 3. Treatment with size $2 \mu \mathrm{M}$ or $40 \mathrm{nM}$ GEN decreased cancer stem-like cell populations in mammosphere cells. (A) The suspension of mammosphere cells (P1) was seeded in the presence of GEN $(2 \mu \mathrm{M}$, and $40 \mathrm{nM})$ or DMSO medium by co-culture with MCF-7 cells for 3 days, followed by flow cytometry analysis of the CD44-APC, CD24-FITC and Epcam-PE labeled cells. We gated ESA positive cells for analyzing the ratio of subpopulation of CD44/CD24 with different treatment. A representative result run in triplicates is shown. (B) GEN $(2 \mu \mathrm{M}$, and $40 \mathrm{nM})$ significantly reduced the percentage of CD44 ${ }^{+} / \mathrm{CD} 24^{-} /$ $\mathrm{ESA}^{+}$in mammospheres cells (P2) compared with controls. Further, the $2 \mu \mathrm{m}$ exhibited a greater suppression effect than the low dose. Data were mean $\pm \mathrm{SD}$; $\mathrm{n}=3,{ }^{*} \mathrm{P}<0.05 ;{ }^{* *} \mathrm{P}<0.01$, relative to the values in controls.

Enzyme-linked immunosorbent assay. MCF-7 cells were seeded at a density of $4 \times 10^{5}$ cultured in phenol red DMEM + FBS, then switched to phenol-red-free DMEM $+10 \%$ charcoal-dextran stripped FBS, supplement with $10^{-10}$ M $17-\beta$ estradiol, $2 \mu \mathrm{M}$ or $40 \mathrm{nM}$ GEN and DMSO, respectively, for $24 \mathrm{~h}$. Cells were washed and cultured with fresh phenol-redfree DMEM for 3 days. Then the fresh conditioned medium and the medium in co-culture condition filtering through a $0.2 \mu \mathrm{m}$ microporous membrane were collected. An enzymelinked immunosorbent assay (ELISA) was used to measure the levels of AREG (Quantikine ELISA, R\&D Systems) and epidermal growth factor (EGF) (Instant ELISA, Ebioscience) in the medium according to the manufacturer's protocol.

Statistical analysis. Three independent experiments were performed and each experiment was conducted in triplicate. Statistical analysis was performed using ANOVA method, least significant difference (LSD) post-hoc test, and independent $\mathrm{t}$-test. $\mathrm{P}<0.05$ was considered to indicate a statistically significant difference.

\section{Results}

GEN inhibits the formation of mammosphere cells (P2) effectively both in solo-culture and co-culture condition. Consistent with a previous study (22), mammospheres as floating spherical colonies could survive and self-renew under serum-free conditions (Fig. 2A). To investigate whether GEN could inhibit mammosphere cell (P2) formation, mammo- sphere formation assay was performed. After 3 days of co-culture, morphological changes of mammospheres (P2) in co-culture condition with MCF-7 cells were displayed (Fig. 2B). Compared to controls, mammosphere cells (P2) with treatment of GEN tended to be smaller, turned into attached state and differentiated into epithelial-like cells (spindle cells similar to MDA-MB-231 cells) individually because they had lost the capacity of initiating. In co-culture and solo-culture condition, treatment with $2 \mu \mathrm{M}$ GEN inhibited mammospheres (P2) formation by $52.4 \%$ and $48.4 \%$ and treatment with $40 \mathrm{nM}$ GEN inhibited mammosphere (P2) formation by 43.8 and $46.9 \%$, respectively (Fig. 2C). Furthermore, no significant difference was found in reduction of the numbers of mammospheres between the co-culture and solo-culture group at the same concentration of GEN $(\mathrm{P}>0.05)$. Both doses of GEN had equal effect on inhibition of mammosphere formation ( $\mathrm{P}>0.05)$ directly or indirectly. However, morphological changes of mammospheres did not exist in solo-culture condition. Therefore, we considered the morphological changes were mainly related to a paracrine effect rather than direct effect.

GEN significantly decreased the $C D 44^{+} / C D 24^{-} / E S A^{+}$population in mammospheres $(P 2)$ under co-culture condition. We found that either $2 \mu \mathrm{M}$ or $40 \mathrm{nM}$ GEN decreased the ratio of population of $\mathrm{CD}_{4} 4^{+} / \mathrm{CD} 24 / \mathrm{ESA}^{+}$in the mammosphere cells (P2) of the bottom chamber in contrast with DMSO group (Fig. 3A). The results showed that after a 3 day co-culture, the treatment of mammosphere cells (P2) with GEN at $2 \mu \mathrm{M}$ and 
Table I. The primers of differentiation-associated and stem cell-associated genes.

\begin{tabular}{ll}
\hline Genes & \multicolumn{1}{c}{ Primers } \\
\hline$\beta$-actin & F: ACGGCATCGTCACCAACTG \\
& R: CAAACATGATCTGGGTCATCTTCTC \\
E-cadherin & F: TGCTAATTCTGATTCTGCTGCTC \\
& R: CCTCTTCTCCGCCTCCT \\
$\alpha$-SMA & F: GGGACATCAAGGAGAAACT \\
& R: CCATCAGGCAACTCGTAA \\
Claudin-1 & F: CTGGGCTCGCTGCTTCT \\
Slug & R: GCCTTGGTGTTGGGTAA \\
& F: GCCAAACTACAGCGAACT \\
Fibronectin & R: GGGCGTGGAATGGA \\
& F: CACCGTGTCGGGATT \\
Snail & F: CCTCGCTGCCAATGCTC \\
& R: GCCTTTCCCACTGTCCTCAT
\end{tabular}

F, Forward (5'-3'); R, Reverse (5'-3').

$40 \mathrm{nM}$ concentration resulted in reduction of $\mathrm{CD}^{4} 4^{+} / \mathrm{CD} 24 \%$ $\mathrm{ESA}^{+}$population by 27.6 and $18.1 \%$, respectively (Fig. 3A). By comparing these results, we concluded that the ratio of CD $44^{+} / \mathrm{CD} 24^{-} / \mathrm{ESA}^{+}$in high dose $(2 \mu \mathrm{M})$ group was modestly lower than that in low dose $(40 \mathrm{nM})$ group indicating that GEN at $2 \mu \mathrm{M}$ had greater inhibitory effects $(\mathrm{P}<0.05)$ (Fig. 3B). To explore the direct effect on altering the ratio of the specific population by GEN, we seeded single-cell suspension mammosphere cells (P1) into ultra-low attachment plates with the same concentration of GEN or DMSO. The result showed that there was no corresponding decrease in $\mathrm{CD}_{4} 4^{+} / \mathrm{CD} 24^{-} / \mathrm{ESA}^{+}$population of mammosphere cells (P2) (data not shown).

GEN affects mRNA expression of markers for differentiated or stem state in mammosphere cells. We examined the mRNA expression of differentiation-associated and stem cell-associated genes with treatment of size $2 \mu \mathrm{M}$, and $40 \mathrm{nM}$ GEN or DMSO, respectively. E-cadherin, $\alpha$-smooth muscle actin ( $\alpha$-SMA) and Claudin-1 genes were reported as differentiation-associated genes while Slug, Snail and Fibronectin genes were reported with the opposite results $(5,10,23)$. As shown in Fig. 4A, GEN upregulated mRNA expression of markers for differentiated cells and downregulated the expression of markers for the stem ones in the mammospheres cells (P2) by co-culture with MCF-7 cells. It was noteworthy that E-cadherin mRNA expression was increased by 19 - and 6-fold in mammosphere cells (P2) treated with $2 \mu \mathrm{M}$ and $40 \mathrm{nM}$ GEN relative to DMSO group, respectively. In solo-culture condition, the expression of relevant genes of mammosphere cells (P2) treated with GEN or DMSO was quantified (Fig. 4B). It was shown that mRNA expression of markers for differentiated cells was not increased, whereas this expression of markers for those representing stem ones was mostly increased. Stem cell-associated genes such as Fibronectin and Snail were increased by GEN in a direct way significantly $(\mathrm{P}<0.01)$.

Differentiation-inducing effect of GEN correlates with PI3K/Akt and MEK/ERK signaling. PI3K/Akt, MEK/ERK, GSK3 $\beta / \beta$-catenin and TGF- $\beta /$ Smad signaling pathways were involved in inducing self-renewal and differentiation of stem cells (24-26). To evaluate whether GEN induced differentiation of BCSCs, western blotting assay was conducted. The results had shown that in co-culture condition, not in solo-culture condition, the levels of phospho-Akt308/473 and phospho-ERK1/2 were elevated in mammosphere cells (P2) compared with controls (Fig. 5A). Additionally, we found the level of phospho- $\beta$-catenin was increased both in co-culture and solo-culture condition (Fig. 5B). There was no significant difference in the expression of total $\beta$-catenin protein in mammospheres representing less $\beta$-catenin accumulation in cytosol, i.e., inactivion of Wnt signaling. However, the amount of phospho-Smad2/3 and TGF- $\beta$ did not differ between GEN ( $2 \mu \mathrm{M}, 40 \mathrm{nM})$ group and DMSO group in co-culture condition (Fig. 5C). Therefore, we supported that activation of PI3K/Akt and MEK/ERK signaling was induced by GEN in a paracrine manner.

Amphiregulin may be involved in differentiation induced by GEN. In the western blotting experiments, PI3K/Akt and MEK/ERK signaling pathways were activated. We hypothesized one or two of EGFR family members were the paracrine factors released by $\mathrm{ER}^{+}$cells referring to previous studies (27-29). We performed enzyme-linked immunosorbent assay to detect paracrine factors including conditioned medium and medium in co-culture system. The results showed that the levels of AREG in co-culture system and conditioned medium were significantly elevated in GEN group relative to controls $(\mathrm{P}<0.05)$. In co-culture medium, GEN at $2 \mu \mathrm{M}$ and $40 \mathrm{nM}$ concentration increased the level of AREG by 6.6- and 2.8-fold, respectively (Fig. 6A), relative to controls. Additionally, in conditioned medium, treatment with GEN (2 $\mu \mathrm{M}, 40 \mathrm{nM})$ increased AREG concentrations to a similar extent (6.6- and 2.9-fold) compared with controls (Fig. 6B). The results also exhibited that the conditioned medium with treatment of $17-\beta$ estradiol $\left(10^{-10} \mathrm{M}\right)$ contained high level (11.2-fold) of AREG confirming the paracrine effect existed in the $\mathrm{ER}^{+}$breast cancer cells by low concentration of estrogen. However, levels of EGF with treatment of GEN or DMSO in co-culture or conditioned medium were not detected (data not shown). As a result, we deduced, AREG was one of the paracrine factors promoting the differentiation of BCSCs.

\section{Discussion}

Some drugs have been found specifically killing CSCs $(30,31)$, whereas, our strategy for focusing BCSCs is searching for a certain drug or compound that can induce differentiation of BCSCs. In our study, Transwell inserts were applied to establish a co-culture model so as to elaborate the interaction between MCF-7 cells and mammosphere cells. The size $0.4 \mu \mathrm{m}$ of membrane of inserts allows small molecules 


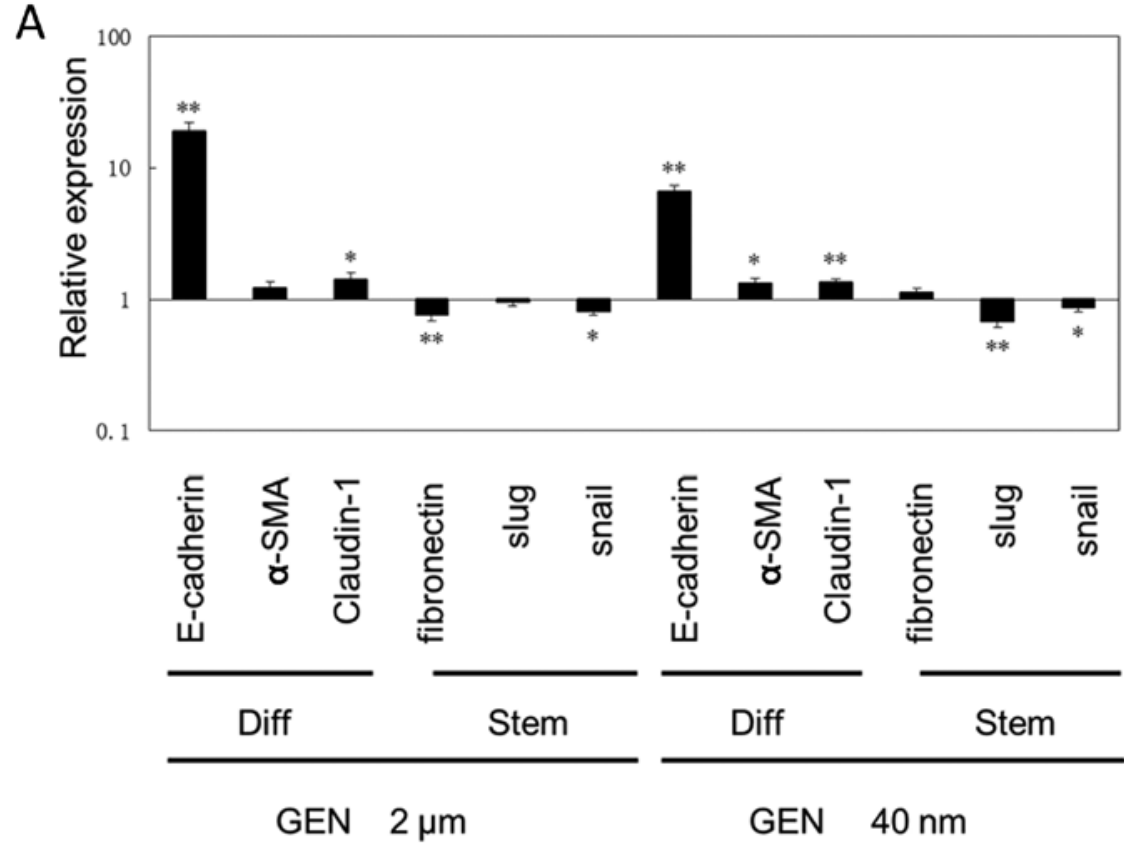

B

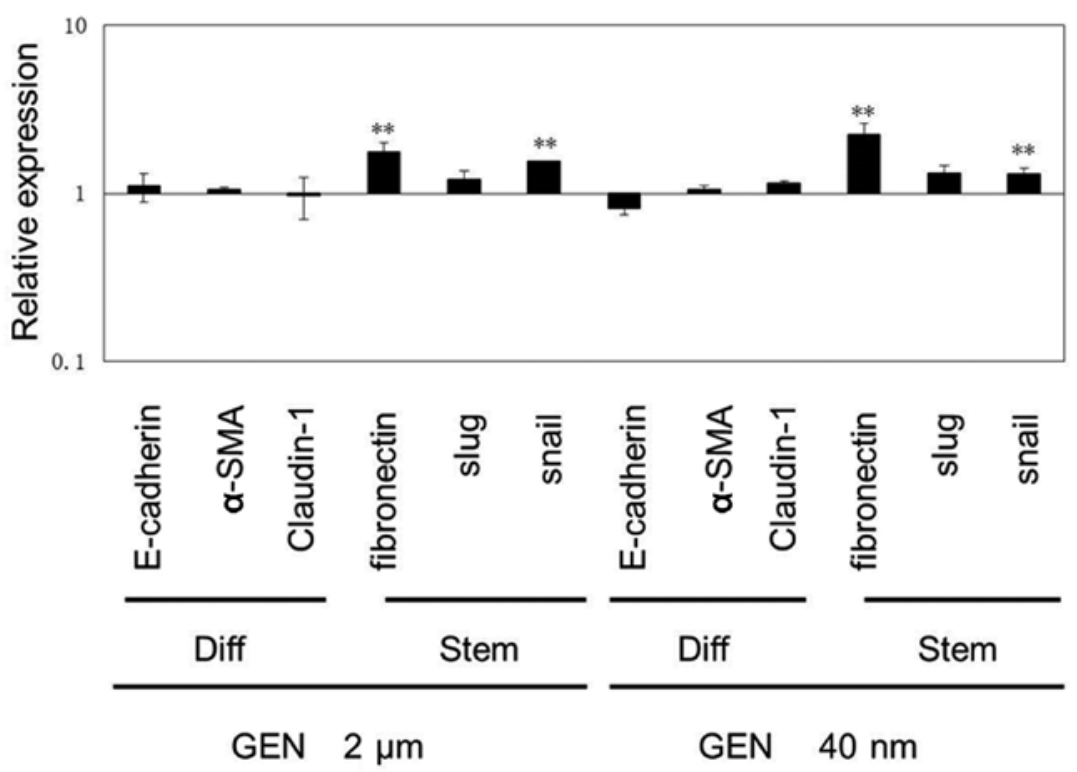

Figure 4. GEN affects the mRNA expression of differentiation-associated and stem cell-associated genes. After a 3 day co-culture or solo-culture, total RNA of mammospheres (P2) was extracted and underwent real-time PCR using specific primers for each gene (Diff, markers for differentiated cells; Stem, markers for stem cells). Values were normalized to the $\beta$-actin gene, expressed relative to the controls. Values shown are the mean $\pm \mathrm{SD}(\mathrm{n}=3-5)$. ${ }^{*} \mathrm{P}<0.05 ;{ }^{* *} \mathrm{P}<0.01$ compared to controls. (A) In co-culture condition, with treatment of GEN $(2 \mu \mathrm{M}, 40 \mathrm{nM})$ or DMSO for 3 days, the variation in expression of indicated genes of mammosphere cells (P2) is displayed. (B) In solo-culture condition, medium containing different levels of GEN induced the expression of stem cell-associated genes of mammosphere cells (P2).

of medium exchange freely, which involves GEN absolutely. To remove the disturbance of the direct effect of GEN on mammosphere cells from MDA-MB-231, medium containing different levels of GEN or DMSO for mammosphere cells was studied as contrast. Previous studies have manifested the concentration range from $40 \mathrm{nM}$ to $2 \mu \mathrm{M}$ in sera of dietary soy food consumers $(32,33)$, therefore the two threshold doses were used in the following experiments. In vitro, a number of aspects were demonstrated to judge the level of differentiation, such as cell morphological change of mammosphere cells, expression of cell surface markers, and upregulation or deregulation of certain genes representing differentiation or stem state.
As our experiments exhibited, in a paracrine manner, the suppression of proliferation of mammosphere cells (P2) combined with morphological changes (from floating spherical cells to adherent spindle cells) is induced by GEN. To verify whether $2 \mu \mathrm{M}$ or $40 \mathrm{nM}$ GEN could target BCSCs, we selected cell surface protein $\mathrm{CD}_{4} 4^{+} / \mathrm{CD} 24^{-} / \mathrm{ESA}^{+}$as BCSCs biomarkers. The reduction of ratio of $\mathrm{CD}_{4} 4^{+} / \mathrm{CD} 24 / \mathrm{ESA}^{+}$which enriches CSCs is found both in $2 \mu \mathrm{M}$ and $40 \mathrm{nM}$ GEN in co-culture condition. However, the higher dose $(2 \mu \mathrm{M})$ GEN demonstrates a more robust restraint of the specific subpopulation. The alteration at transcription level by GEN includes upregulation of the expression of differentiation-associated genes and 

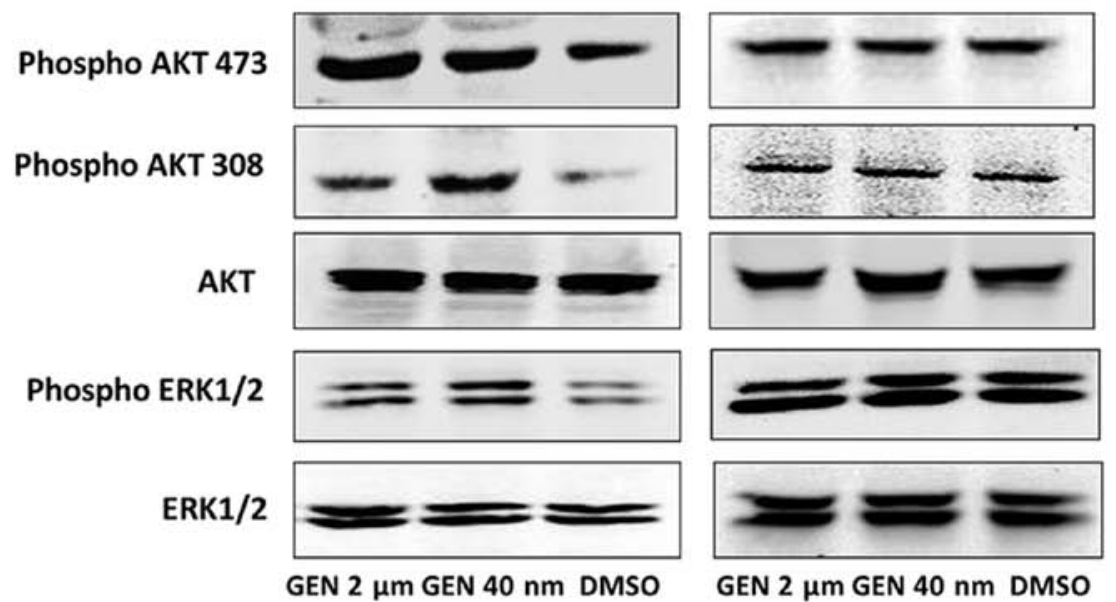

GEN $2 \mu \mathrm{m}$ GEN $40 \mathrm{~nm}$ DMSO
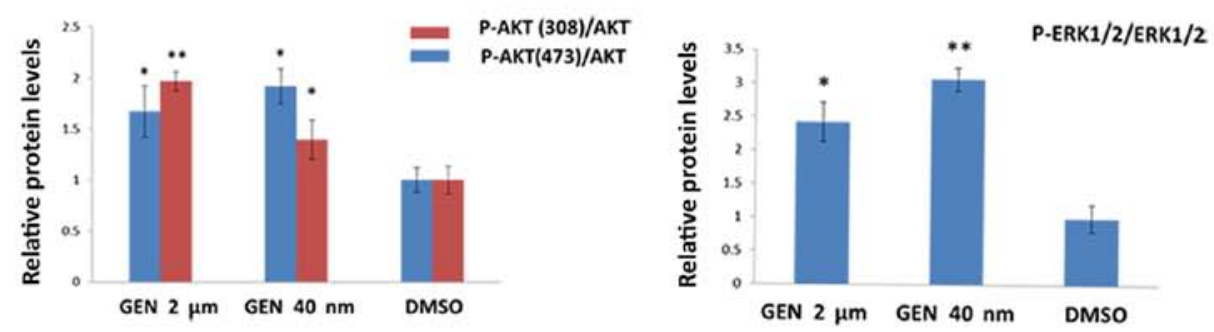

B

\section{Co-cultured mammospheres Solo-cultured mammospheres.}

Phospho $\beta$-catenin
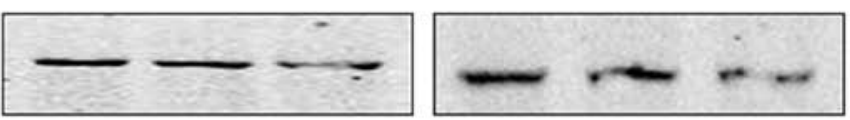

\section{$\beta$-catenin}
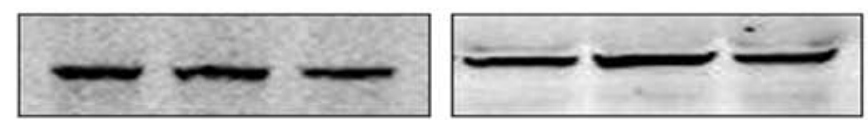

GSK3 $\beta$
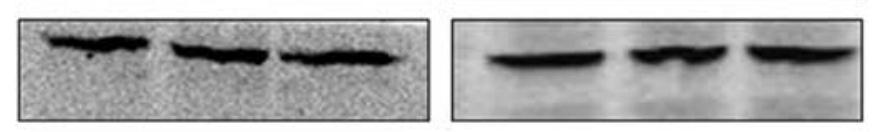

$\beta$-actin
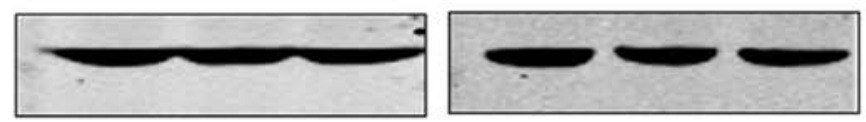

GEN2 $\mu \mathrm{m}$ GEN40 nm DMSO GEN2 $\mu \mathrm{m}$ GEN40 nm DMSO

C

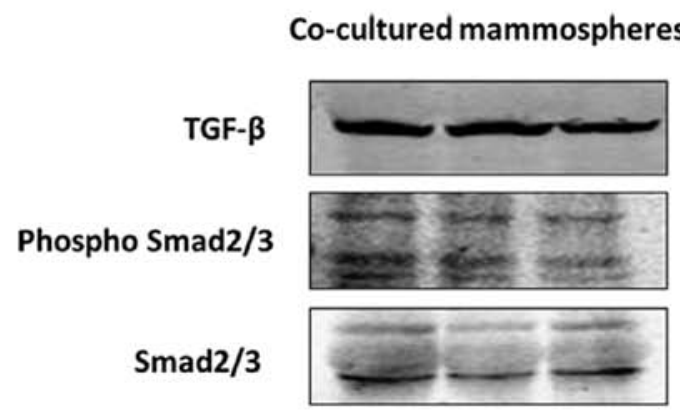

GEN2 $\mu \mathrm{m}$ GEN40 nm DMSO

Figure 5. PI3K/Akt and MEK/ERK signaling pathways are activated by GEN through a paracrine mechanism. (A) phospho-Akt (308), phospho-Akt (473), total Akt, phospho-ERK1/2 and total ERK1/2 protein levels in mammospheres after a 3 day treatment with GEN or DMSO were analyzed by western blotting. Graphs showed the relative expression levels for phospho-Akt 308/473 and phospho-ERK1/2 in co-culture condition. ${ }^{*} \mathrm{P}<0.05 ;{ }^{* *} \mathrm{P}<0.01$ relative to control group. (B) phospho- $\beta$-catenin protein levels were upregulated both in co-culture and solo-culture condition. $\beta$-catenin and GSK3 $\beta$ protein level in co-culture or solo-culture condition were also analyzed by western blotting. (C) TGF- $\beta$, phospho-Smad2/3 and total Smad2/3 protein levels in mammospheres of co-culture conditions were analyzed. 

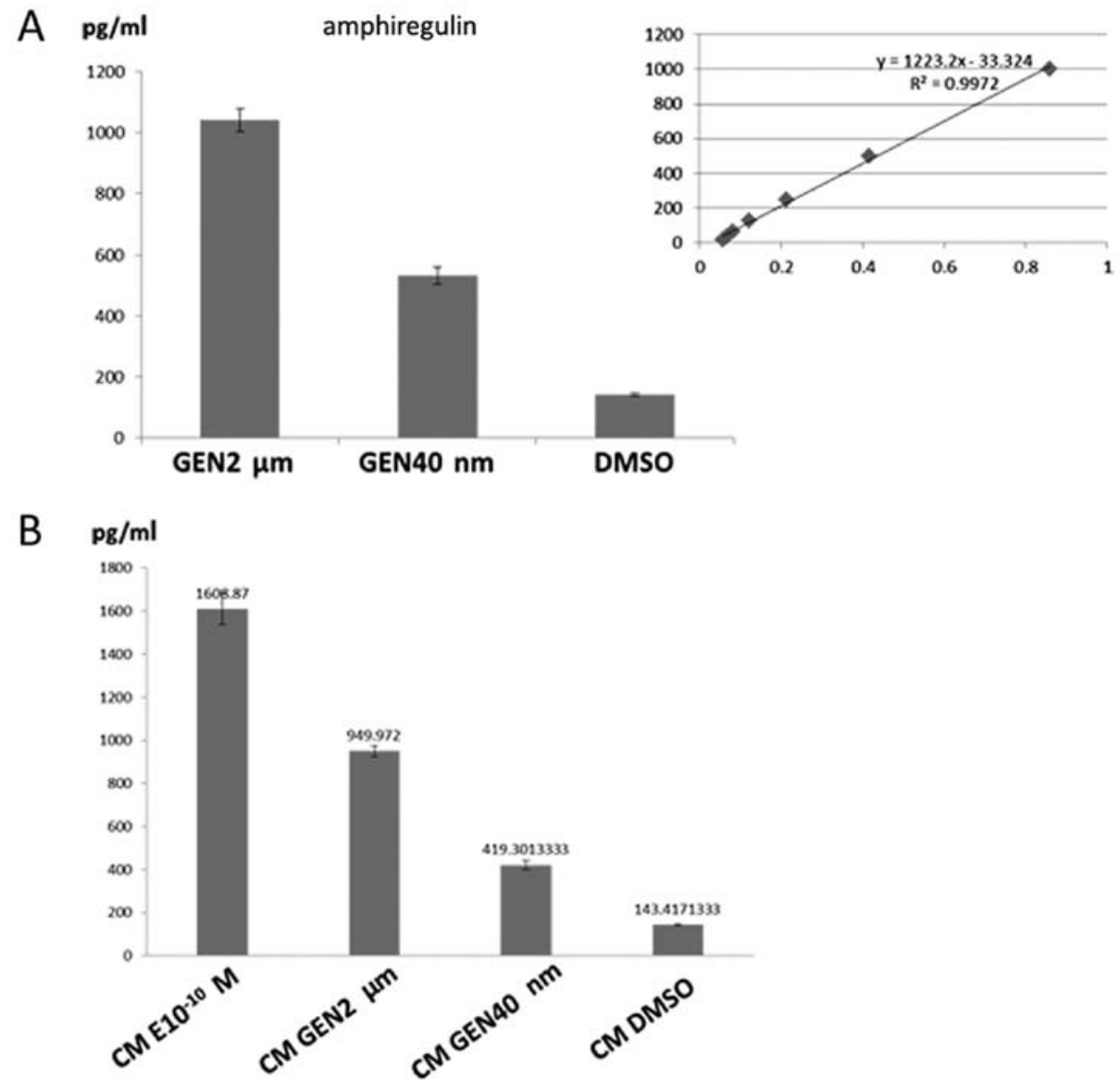

Figure 6. GEN $(2 \mu \mathrm{M}$, and $40 \mathrm{nM})$ effectively acted on $\mathrm{ER}^{+}$positive cells secreting AREG. (A) Concentrations of AREG were measured in medium of co-culture condition after a 3 day exposure to GEN or DMSO in MCF-7 cells. Values are expressed as mean $\pm \mathrm{SD}(\mathrm{n}=3) .{ }^{* *} \mathrm{P}<0.01$ relative to controls. (B) Concentrations of AREG were measured in the conditioned medium after $24 \mathrm{~h}$ exposure to $10^{-10} \mathrm{M} 17-\beta$ estradiol, GEN $(2 \mu \mathrm{M}, 40 \mathrm{nM})$ or DMSO. Values are expressed as mean $\pm \mathrm{SD}(\mathrm{n}=3)^{* *} \mathrm{P}<0.01$, relative to the values in the respective controls. $\mathrm{CM}$, conditioned medium; E, 17- $\beta$ estradiol.

downregulation of the expression of stem cell-associated ones in co-culture condition, respectively. In solo-culture condition, GEN decreases the population of BCSCs to a similar extent without morphological changes, which is also proved by other groups (34). Medium containing $2 \mu \mathrm{M}$ or $40 \mathrm{nM}$ GEN does not have an effect on the ratio of specific subpopulation of mammosphere cells, but upregulates stem cell-associated genes (Fibronection and Snail). Thus, we can conclude that GEN not only decreases the number of mammospheres derived from MDA-MB-231 cells but also promotes the differentiation of mammosphere cells in a paracrine manner. It is assumed that GEN has influence on the number of mammospheres, but not on the morphological changes and the ratio of $\mathrm{CD}_{4} 4^{+} / \mathrm{CD} 24^{-} /$ $\mathrm{ESA}^{+}$among the mammospheres directly.

It is known that activated canonical Wnt signaling by $\beta$-catenin tends to facilitate cell growth and inhibits differentiation (35). It is noteworthy that both in co-culture and solo-culture condition, phospho- $\beta$-catenin protein levels are increased concerning unchanged total $\beta$-catenin protein levels, which represents that the amount of $\beta$-catenin for ubiquination/degradation is elevated. However, the process does not have significant alteration of GSK3 $\beta$ protein levels, which indicates the process is probably not mediated by activation of GSK3 $\beta$ protein. Some studies have shown that the inhibition of $\beta$-catenin-mediated Wnt signaling by GEN is partly through increasing E-cadherin protein or enhancing secreted frizzled-related protein-2 (Sfrp-2) (34,36-38). The suppression of Wnt signaling in co-culture and solo-culture condition may account for the inhibition effect on mammosphere formation by GEN.

Though activation of both PI3K/Akt and MEK/ERK signaling pathways is demonstrated in our present data, their precise roles in differentiation of BCSCs have not been confirmed. As to MEK/ERK signaling, similar effects have been clarified in other systems including mammary epithelial cells (MECs) and embryonic stem cells. Sustained activation of ERK by TGF- $\alpha$ in primary mouse MECs gives rise to branching morphogenesis (39). Additionally, in human MECs, sustained activation of ERK by EGF accelerates appearance of myoepithelial cells to promote differentiation (40). On the other hand, the role that PI3K/Akt signaling plays in maintenance and differentiation of stem/progenitor or epithelial cell remains intricate and controversial $(26,41,42)$. In mammary epithelial cells, studies show that the expression of phosphatase and tensin homolog (PTEN), a negative regulator, is upregulated by GEN which is considered to antagonize the PI3K/Akt pathway $(43,44)$. Generally, GEN is developed and used as a protein tyrosine kinase inhibitor and an ER agonist to block PI3K/Akt activation. Nevertheless, with treatment of GEN, the level of phospho-Akt 308/473 expression in soloculture mammosphere cells does not differ according to our study, which means the inhibition of PI3K/Akt signaling 
by GEN in breast cancer is probably mediated by ER (30) or the concentration of GEN is not appropriate for suppression (45). Given that mammosphere cells from MDA-MB-231 cells lack ER and PR expression (46,47), GEN as a kind of phytoestrogen could not bind to ER to have antiproliferative effects by reduction of PI3K/Akt signaling. Noteworthy, the level of phospho-Akt 308/473 of mammosphere cells (P2) in co-culture system is evaluated, which further elucidates that MCF-7 cells with treatment of GEN have released certain factors causing mammosphere differentiation by altering corresponding down-stream signaling pathways.

In Transwell co-culture system, with GEN acting on upper chamber cells, the levels of phosphorylation of the above two signaling pathways are increased while GEN, when administered as a part of the medium, could not function directly. In consequence, we focus on the upstream of the two major pathway, EGFR ligands (EGF, AREG, TGF- $\alpha$ ), one or two of which probably could be the key paracrine factor. Our initial hypothesis before the study was that GEN as phytoestrogen can also regulate $\mathrm{ER}^{-}$stem cell differentiation mediated by $\mathrm{ER}^{+}$cells. Eventually it is confirmed by the enzyme linked immunoabsorbent assay demonstrating that GEN may act on MCF-7 cells in the inserts eliciting AREG in the medium which in turn promotes the differentiation of cells in the bottom chamber. To address whether AREG in the medium is secreted by MCF-7 cells or AREG autocrine regulation exists, conditioned medium was obtained to conduct the assay and similar results were seen in the conditioned medium of both doses of GEN. By comparison, the higher GEN dose $(2 \mu \mathrm{M})$ displays a more robust release of AREG levels, which is consistent with the greater inhibition of the subpopulation of $\mathrm{CD} 44^{+} / \mathrm{CD} 24 \% \mathrm{ESA}^{+}$and the higher expression of E-cadherin transcript levels. Ciarloni et al found that in mammary gland, $17-\beta$ estradiol stimulates release of AREG through the ER and requires AREG for terminal end buds formation in mice during puberty (48).

In our study, $10^{-10} \mathrm{M} 17-\beta$ estradiol markedly increased the level of AREG in the conditioned medium, but inevitably promoted $\mathrm{ER}^{+}$breast cancer cells proliferation (49), which is not the outcome we expected. Some researchers have reported that estrogen may expand the pool of BCSCs in a paracrine manner $(46,50)$. In contrast, our results show that GEN at physiological concentration ( $40 \mathrm{nM}-2 \mu \mathrm{M})$ displays anti-mammary tumor effects thus manifesting that GEN exerts antiestrogenic effects consistent with others $(34,37)$.

\section{Acknowledgements}

We thank Xiaojun Wang from Harbin Veterinary Research Institute for providing help. This study was supported by grants from the National Natural Science Foundation of China (grant no. 81270034).

\section{References}

1. Wu C and Alman BA: Side population cells in human cancers Cancer Lett 268: 1-9, 2008.

2. Dave B and Chang J: Treatment resistance in stem cells and breast cancer. J Mammary Gland Biol Neoplasia 14: 79-82, 2009

3. Visvader JE and Lindeman GJ: Cancer stem cells in solid tumours: Accumulating evidence and unresolved questions. Nat Rev Cancer 8: 755-768, 2008.
4. Li X, Lewis MT, Huang J, Gutierrez C, Osborne CK, Wu MF, Hilsenbeck SG, Pavlick A, Zhang X, Chamness GC, et al: Intrinsic resistance of tumorigenic breast cancer cells to chemotherapy. J Natl Cancer Inst 100: 672-679, 2008.

5. Creighton CJ, Li X, Landis M, Dixon JM, Neumeister VM, Sjolund A, Rimm DL, Wong H, Rodriguez A, Herschkowitz JI, et al: Residual breast cancers after conventional therapy display mesenchymal as well as tumor-initiating features. Proc Nat Acad Sci USA 106: 13820-13825, 2009.

6. Takehara M, Hoshino T, Namba T, Yamakawa $\mathrm{N}$ and Mizushima T: Acetaminophen-induced differentiation of human breast cancer stem cells and inhibition of tumor xenograft growth in mice. Biochem Pharmacol 81: 1124-1135, 2011.

7. Al-Hajj M, Wicha MS, Benito-Hernandez A, Morrison SJ and Clarke MF: Prospective identification of tumorigenic breast cancer cells. Proc Natl Acad Sci USA 100: 3983-3988, 2003.

8. Singh SK, Clarke ID, Terasaki M, Bonn VE, Hawkins C, Squire J and Dirks PB: Identification of a cancer stem cell in human brain tumors. Cancer Res 63: 5821-5828, 2003.

9. Ricci-Vitiani L, Lombardi DG, Pilozzi E, Biffoni M, Todaro M, Peschle $C$ and De Maria R: Identification and expansion of human colon-cancer-initiating cells. Nature 445: 111-115, 2007.

10. Mani SA, Guo W, Liao MJ, Eaton EN, Ayyanan A, Zhou AY, Brooks M, Reinhard F, Zhang CC, Shipitsin M, et al: The epithelial-mesenchymal transition generates cells with properties of stem cells. Cell 133: 704-715, 2008

11. Ponti D, Costa A, Zaffaroni N, Pratesi G, Petrangolini G, Coradini D, Pilotti S, Pierotti MA and Daidone MG: Isolation and in vitro propagation of tumorigenic breast cancer cells with stem/progenitor cell properties. Cancer Res 65: 5506-5511, 2005.

12. Korach KS, Couse JF, Curtis SW, Washburn TF, Lindzey J, Kimbro KS, Eddy EM, Migliaccio S, Snedeker SM, Lubahn DB, et al: Estrogen receptor gene disruption: molecular characterization and experimental and clinical phenotypes. Recent Prog Horm Res 51: 159-186; discussion 186-158, 1996.

13. O'Brien CS, Farnie G, Howell SJ and Clarke RB: Breast cancer stem cells and their role in resistance to endocrine therapy. Horm Cancer 2: 91-103, 2011.

14. Dontu G, El-Ashry D and Wicha MS: Breast cancer, stem/ progenitor cells and the estrogen receptor. Trends Endocrinol Metab 15: 193-197, 2004.

15. Rizvi AZ and Wong MH: Epithelial stem cells and their niche: There's no place like home. Stem Cells 23: 150-165, 2005.

16. Lin H: The stem-cell niche theory: Lessons from flies. Nat Rev Genet 3: 931-940, 2002.

17. Wu AH, Wan P, Hankin J, Tseng CC, Yu MC and Pike MC: Adolescent and adult soy intake and risk of breast cancer in Asian-Americans. Carcinogenesis 23: 1491-1496, 2002.

18. Iwasaki M, Inoue M, Otani T, Sasazuki S, Kurahashi N, Miura T, Yamamoto S and Tsugane S; Japan Public Health Center-based prospective study group: Plasma isoflavone level and subsequent risk of breast cancer among Japanese women: A nested casecontrol study from the Japan Public Health Center-based prospective study group. J Clin Oncol 26: 1677-1683, 2008.

19. Dewi FN, Wood CE, Lees CJ, Willson CJ, Register TC, Tooze JA, Franke AA and Cline JM: Dietary soy effects on mammary gland development during the pubertal transition in nonhuman primates. Cancer Prev Res (Phila) 6: 832-842, 2003.

20. Duffy C, Perez K and Partridge A: Implications of phytoestrogen intake for breast cancer. CA Cancer J Clin 57: 260-277, 2007.

21. Martin PM, Horwitz KB, Ryan DS and McGuire WL: Phytoestrogen interaction with estrogen receptors in human breast cancer cells. Endocrinology 103: 1860-1867, 1978.

22. Shu XO, Jin F, Dai Q, Wen W, Potter JD, Kushi LH, Ruan Z, Gao YT and Zheng W: Soyfood intake during adolescence and subsequent risk of breast cancer among Chinese women. Cancer Epidemiol Biomarkers Prev 10: 483-488, 2001.

23. Verheus M, van Gils CH, Keinan-Boker L, Grace PB, Bingham SA and Peeters PH: Plasma phytoestrogens and subsequent breast cancer risk. J Clin Oncol 25: 648-655, 2007.

24. Dontu G, Abdallah WM, Foley JM, Jackson KW, Clarke MF, Kawamura MJ and Wicha MS: In vitro propagation and transcriptional profiling of human mammary stem/progenitor cells. Genes Dev 17: 1253-1270, 2003.

25. Shipitsin M, Campbell LL, Argani P, Weremowicz S, BloushtainQimron N, Yao J, Nikolskaya T, Serebryiskaya T, Beroukhim R, $\mathrm{Hu}$ M, et al: Molecular definition of breast tumor heterogeneity. Cancer Cell 11: 259-273, 2007. 
26. Korkaya H, Paulson A, Charafe-Jauffret E, Ginestier C, Brown M, Dutcher J, Clouthier SG and Wicha MS: Regulation of mammary stem/progenitor cells by PTEN/Akt/beta-catenin signaling. PLoS Biol 7: e1000121, 2009.

27. Singh AM, Reynolds D, Cliff T, Ohtsuka S, Mattheyses AL, Sun Y, Menendez L, Kulik M and Dalton S: Signaling network crosstalk in human pluripotent cells: A Smad2/3-regulated switch that controls the balance between self-renewal and differentiation. Cell Stem Cell 10: 312-326, 2012.

28. Watabe T and Miyazono K: Roles of TGF- $\beta$ family signaling in stem cell renewal and differentiation. Cell Res 19: 103-115, 2009.

29. Mukhopadhyay C, Zhao X, Maroni D, Band V and Naramura M: Distinct effects of EGFR ligands on human mammary epithelial cell differentiation. PLoS One 8: e75907, 2013.

30. Chen FP and Chien MH: Phytoestrogens induce differential effects on both normal and malignant human breast cells in vitro Climacteric 17: 682-691, 2014.

31. Yang H, Sun DK, Chen D, Cui QC, Gu YY, Jiang T, Chen W, Wan SB and Dou QP: Antitumor activity of novel fluorosubstituted (-)-epigallocatechin-3-gallate analogs. Cancer Lett 292: 48-53, 2010

32. Gupta PB, Onder TT, Jiang G, Tao K, Kuperwasser C, Weinberg RA and Lander ES: Identification of selective inhibitors of cancer stem cells by high-throughput screening. Cell 138: 645-659, 2009.

33. Hirsch HA, Iliopoulos D, Tsichlis PN and Struhl K: Metformin selectively targets cancer stem cells, and acts together with chemotherapy to block tumor growth and prolong remission. Cancer Res 69: 7507-7511, 2009.

34. Montales MT, Rahal OM, Kang J, Rogers TJ, Prior RL, Wu X and Simmen RC: Repression of mammosphere formation of human breast cancer cells by soy isoflavone genistein and blueberry polyphenolic acids suggests diet-mediated targeting of cancer stem-like/progenitor cells. Carcinogenesis 33: 652-660, 2012.

35. Clevers $\mathrm{H}$ : Wnt/beta-catenin signaling in development and disease. Cell 127: 469-480, 2006.

36. Akiyama T: Wnt/beta-catenin signaling. Cytokine Growth Factor Rev 11: 273-282, 2000.

37. Su Y and Simmen RC: Soy isoflavone genistein upregulates epithelial adhesion molecule E-cadherin expression and attenuates beta-catenin signaling in mammary epithelial cells. Carcinogenesis 30: 331-339, 2009.

38. Su Y, Simmen FA, Xiao R and Simmen RC: Expression profiling of rat mammary epithelial cells reveals candidate signaling pathways in dietary protection from mammary tumors. Physiol Genomics 30: 8-16, 2007.

39. Fata JE, Mori H, Ewald AJ, Zhang H, Yao E, Werb Z and Bissell MJ: The MAPK(ERK-1,2) pathway integrates distinct and antagonistic signals from TGFalpha and FGF7 in morphogenesis of mouse mammary epithelium. Dev Biol 306: 193-207, 2007.
40. Pasic L, Eisinger-Mathason TS, Velayudhan BT, Moskaluk CA, Brenin DR, Macara IG and Lannigan DA: Sustained activation of the HER1-ERK1/2-RSK signaling pathway controls myoepithelial cell fate in human mammary tissue. Genes Dev 25: 1641-1653, 2011.

41. Li G, Robinson GW, Lesche R, Martinez-Diaz H, Jiang Z, Rozengurt N, Wagner KU, Wu DC, Lane TF, Liu X, et al: Conditional loss of PTEN leads to precocious development and neoplasia in the mammary gland. Development 129: 4159-4170, 2002.

42. Chen C-C, Stairs DB, Boxer RB, Belka GK, Horseman ND, Alvarez JV and Chodosh LA: Autocrine prolactin induced by the Pten-Akt pathway is required for lactation initiation and provides a direct link between the Akt and Stat5 pathways. Genes Dev 26: 2154-2168, 2012

43. Dave B, Eason RR, Till SR, Geng Y, Velarde MC, Badger TM and Simmen RC: The soy isoflavone genistein promotes apoptosis in mammary epithelial cells by inducing the tumor suppressor PTEN. Carcinogenesis 26: 1793-1803, 2005.

44. Rahal OM and Simmen RC: PTEN and p53 cross-regulation induced by soy isoflavone genistein promotes mammary epithelial cell cycle arrest and lobuloalveolar differentiation. Carcinogenesis 31: 1491-1500, 2010.

45. Fang CY, Tseng $M$ and Daly MB: Correlates of soy food consumption in women at increased risk for breast cancer. J Am Diet Assoc 105: 1552-1558, 2005.

46. Fillmore CM, Gupta PB, Rudnick JA, Caballero S, Keller PJ, Lander ES and Kuperwasser C: Estrogen expands breast cancer stem-like cells through paracrine FGF/Tbx3 signaling. Proc Natl Acad Sci USA 107: 21737-21742, 2010.

47. Joshi PA, Jackson HW, Beristain AG, Di Grappa MA, Mote PA, Clarke CL, Stingl J, Waterhouse PD and Khokha R: Progesterone induces adult mammary stem cell expansion. Nature 465: 803-807, 2010

48. Ciarloni L, Mallepell S and Brisken C: Amphiregulin is an essential mediator of estrogen receptor alpha function in mammary gland development. Proc Natl Acad Sci USA 104: 5455-5460, 2007.

49. Medina D: Mammary developmental fate and breast cancer risk. Endocr Relat Cancer 12: 483-495, 2005

50. Harrison H, Simões BM, Rogerson L, Howell SJ, Landberg G and Clarke RB: Oestrogen increases the activity of oestrogen receptor negative breast cancer stem cells through paracrine EGFR and Notch signalling. Breast Cancer Res 15: R21, 2013. 